\title{
Ventriculitis asociada a drenaje extraventricular: etiología, diagnóstico y tratamiento enfocado a unidades de cuidados neurocríticos
}

\author{
Ventriculitis associated with extraventricular drainage: etiology, diagnosis and treatment \\ focused on neurocritic care units
}

Liezel Ulloque-Caamaño1, Joulen Mo-Carrascal', Johana Maraby ${ }^{1}$, Alexis Narvaez-Rojas², Loraine Quintana-Pajaro ${ }^{3}$, Yancarlos Ramos-Villegas ${ }^{3}$ y Luis R. Moscote-Salazar *

${ }^{1}$ Facultad de Medicina, Universidad de Cartagena, Cartagena de Indias, Colombia; ${ }^{2}$ Cartagena Neurotrauma Research Group, Universidad Nacional Autónoma de Nicaragua, Managua, Nicaragua; ${ }^{3}$ Cartagena Neurotrauma Research Group, Universidad de Cartagena, Cartagena de Indias, Colombia

\begin{abstract}
Resumen
La ventriculitis posterior a un drenaje extraventicular constituye una complicación neuroquirúrgica muy importante en las unidades de cuidados neurocríticos. Se hace necesario realizar un diagnóstico precoz, dado que la morbimortalidad secundaria a esta puede ser variable y complicar la evolución de los pacientes neurocríticos. A pesar de esto, la ventriculostomía continúa siendo un pilar importante en el monitoreo y el tratamiento. Ante la urgencia de ventriculitis asociadas a gérmenes multirresistentes han surgido nuevos fármacos antimicrobianos como parte del tratamiento, al igual que se han propuesto vías intraventriculares dentro de las nuevas investigaciones. Sin embargo, lo anterior aún no tiene bases suficientes para poder sustentarlo. La presente revisión se realizó con el objetivo de contribuir a un diagnóstico precoz y al tratamiento de la ventriculitis asociada a drenaje extraventricular en pacientes neurocríticos, y de esta forma poder mejorar la sobrevida y prevenir desenlaces fatales en estos pacientes.
\end{abstract}

PALABRAS CLAVE: Ventriculitis. Ventriculostomía. Líquido cefalorraquídeo.

\begin{abstract}
Ventriculitis after extraventricular drainage is a very important neurosurgical complication in neurocritical care units. It is necessary to make an early diagnosis, given that the morbidity and mortality secondary to it can be variable, and complicate the evolution of neurocritical patients. Despite this, ventriculostomy continues to be an important pillar in monitoring and treatment. Given the urgency of ventriculitis associated with multiresistant germs, new antimicrobial drugs have emerged as part of the treatment, as intraventricular routes have been proposed within the new investigations. However, the foregoing does not yet have sufficient bases to be able to support it. The present review was carried out with the aim of contributing to an early diagnosis and treatment of ventriculitis associated with extra ventricular drainage in neurocritical patients, and in this way to contribute to improve survival and prevent fatal outcomes in these patients.
\end{abstract}

KEY WORDS: Ventriculitis. Ventriculostomy. Cerebrospinal fluid.

\section{Correspondencia:}

*Luis R. Moscote-Salazar

Campus de Zaragocilla 24a, Ctra. 50a \#2463

Cartagena de Indias, Colombia

E-mail: mineurocirujano@aol.com
Fecha de recepción: 04-01-2018

Fecha de aceptación: 10-10-2018

DOI: $10.24875 / C I R U .18000052$
Cir Cir. 2019;87:230-240

Contents available at PubMed www.cirugiaycirujanos.com 


\section{Introducción}

Los catéteres ventriculares externos o ventriculostomía son una de las derivaciones externas de líquido cefalorraquídeo (LCR) y consisten en un catéter temporal colocado a nivel intraventricular (su ubicación más frecuente), sin sistema valvular, por lo general con un trayecto subcutáneo tunelizado y en conexión con el exterior $^{1,2}$. Son elementos importantes en neurocirugía y en las unidades de cuidados neurocríticos. Cada vez con más frecuencia se utilizan en pacientes con lesión traumática cerebral y también en casos de hemorragias intraventriculares para la evacuación de LCR².

Estos dispositivos se utilizan con fines diagnósticos y terapéuticos, con tres indicaciones fundamentales: 1) monitorización de la presión intracraneal; 2) drenaje de LCR para el tratamiento de la hipertensión intracraneal, la hidrocefalia o ambas; y 3) administración intratecal de fármacos (antibióticos, fibrinolíticos, etc. $)^{3}$.

La derivación de LCR es uno de los procedimientos neuroquirúrgicos más frecuentes: en los EE.UU. se implantan 40.000 derivaciones al año'. Sin embargo, el uso de catéteres ventriculares externos se asocia a un mayor riesgo de infecciones del sistema nervioso central (SNC), como por ejemplo meningitis y ventriculitis, que inciden en un aumento de la mortalidad del $10-20 \%{ }^{3}$.

La ventriculitis es la inflamación de las paredes de los ventrículos cerebrales secundaria a una infección, y su importancia radica en su difícil diagnóstico, que puede estar interferido por la patología que motivó la colocación del catéter; además, prolonga la estancia hospitalaria y eventualmente aumenta los gastos asistenciales ${ }^{2,4}$. Su tasa de incidencia varía del 0 al $45 \%$, lo cual puede deberse a la falta de consenso de los criterios para su diagnóstico ${ }^{6}$.

La ventriculitis puede ser temprana si se presenta en los primeros 10 días de la colocación de la derivación, o tardía si aparece después de los 10 días?.

En 2014, el consenso internacional multidisciplinario sobre monitoreo multimodal declaró que la incidencia de infecciones relacionadas con la ventriculostomía puede ser un indicador útil de la calidad de la atención de las unidades de cuidados intensivos ${ }^{6}$.

\section{Etiopatogenia}

En las derivaciones externas, los microorganismos aislados con mayor frecuencia son los cocos grampositivos (25-56\%) provenientes de la piel, como estafilococos coagulasa negativos (8-33\%), Staphylococcus aureus (11-17\%) y Staphylococcus epidermidis, seguidos de bacilos gramnegativos (50\%) por lo general nosocomiales y multirresistentes, como Pseudomonas aeruginosa (33\%), Klebsiella pneumoniae (22-25\%), Enterobacter spp. (8-11\%) y Serratia marcescens ( $8 \%$ ). Cada vez más se ha visto la presencia de bacilos gramnegativos, los cuales son un problema terapéutico porque están asociados a multirresistencia ${ }^{1,2,8-10}$.

El principal mecanismo patogénico de las infecciones de las derivaciones ventriculares externas es la infección retrógrada desde el catéter, donde el microorganismo progresa desde la piel de forma retrógrada y extraluminal por el catéter hasta el trépano y el LCR. El riesgo de infección aumenta a partir de los 5-7 días de la colocación. Se ha visto que, al quinto día de la cirugía, con un trayecto tunelizado de $5 \mathrm{~cm}$, el trépano craneal está colonizado por los mismos gérmenes que el orificio de salida del catéter. El riesgo de que ocurra este tipo de infección aumenta con las inserciones directas (sin trayecto tunelizado) y cuando hay otra infección concomitante. También puede presentarse una infección intraluminal mientras se manipulan los catéteres para toma de muestras o administración de medicamentos. Otro mecanismo frecuente es mediante la contaminación del catéter durante el acto quirúrgico, desde la piel adyacente y por vía hematógena ${ }^{1,9}$.

La infección de una derivación de LCR está determinada por las características del biomaterial, los mecanismos de defensa del huésped y los factores de virulencia bacteriana. EI SNC, desde el punto de vista inmunitario, tiene menos respuesta a las infecciones debido a que presenta menos concentraciones de complemento y capacidad de opsonización, además de una fagocitosis menos eficiente. Por otra parte, en las superficies del catéter (extraluminal e intraluminal) se depositan proteínas y glucoproteínas (fibrina, elastina, fibronectina, colágeno, etc.) que facilitan la adhesión bacteriana a los biomateriales y conforman el inicio de la biocapa, la cual es un conglomerado de bacterias de distintas especies recubierta por una matriz de exopolisacáridos y productos de degeneración bacteriana, adheridas a las superficies interna y externa de biomateriales y mucosas. El problema de la formación de la biocapa es que protege a las bacterias de los antibióticos, siendo susceptibles a estos las bacterias superficiales, pero no las de su interior, por lo que se requieren dosis muy elevadas de 
antibiótico para que sea efectivo. Otro inconveniente que resulta de esta formación es la aparición de resistencia antibiótica, ya que dentro de ella hay un aumento de transferencia genética entre las bacterias. También puede producirse un desprendimiento de células aisladas o de conglomerados bacterianos que propicien la extensión de la infección a distancia, y la biocapa puede ocasionar la obstrucción de la derivación. La formación de la biocapa ha llevado al uso de catéteres impregnados con antibióticos ${ }^{1,9}$.

\section{Factores de riesgo}

Los factores de riesgo para ventriculitis relacionada con catéter externo de drenaje ventricular se pueden agrupar de la siguiente forma:

- Factores intrínsecos del huésped, como edad (prematuros y ancianos), inmunodepresión por la cirugía, medicamentos o por enfermedad de base, proceso principal, enfermedades previas 0 concomitantes, lesiones cutáneas, infecciones concomitantes en otro lugar, hemorragia intraventricular o subaracnoidea, malformaciones del tubo neural, traumatismo craneoencefálico con fractura craneal y fístula del LCR, craniotomía, hipertensión intracraneal mayor de $20 \mathrm{~cm}$ de $\mathrm{H}_{2} \mathrm{O}$, utilización de neuroendoscopio o neurocirugía previa.

- Factores vinculados al procedimiento neuroquirúrgico, como no seguimiento de un protocolo estandarizado para su colocación, técnica de colocación del catéter, duración del acto quirúrgico, experiencia del neurocirujano, inadecuado control hemostático, necesidad de colocar varias derivaciones ventriculares externas, estado previo y preparación deficiente de la piel y afeitado, exposición de grandes superficies cutáneas durante la intervención, número de personas en el quirófano y movimiento en este, cierre de la herida, disminución de aire dentro del sistema en el momento de la colocación, manipulación del catéter en la intervención, y lugar de realización del procedimiento (quirófano, urgencias, unidad de cuidados intensivos).

- Factores propios del catéter intracraneano, como infecciones previas del catéter, material y tipo de catéter, pues se ha visto que la tasa de infección puede aumentar hasta tres veces después de 18 días de implantado un catéter convencional de silicio, y que hay mayor riesgo de infección con un catéter convencional en comparación con los catéteres impregnados con antibiótico, nanopartículas (plata) y metálicos flexibles; también, lugar de emplazamiento, tiempo de permanencia (mayor de 5-7 días, aunque es controvertido), fístula de LCR asociada, tipo de cirugía, sistemas abiertos, catéteres no tunelizados, drenaje de LCR hemorrágico y fugas pericatéter del LCR.

- Factores extrínsecos, como cuidados posoperatorios, uso de corticoides, manipulación frecuente de la derivación ventricular externa para revisiones, lavado con solución salina fisiológica en caso de disfunción del catéter, drenaje o toma de muestras de LCR o aplicación de medicamento intratecal, inadecuada asepsia antes de la manipulación y hospitalización prolongada ${ }^{1-5,8,10-14}$.

\section{Manifestaciones clínicas}

La infección de las derivaciones externas de LCR puede ocasionar una ventriculitis que se manifiesta por un cambio en el nivel de relación previo del paciente, febrícula, variación en el aspecto del LCR, clínica de hidrocefalia (por obstrucción del drenaje, como cefalea, náuseas, vómitos y alteraciones en el comportamiento) y más raramente convulsiones. Si es muy intensa, pueden aparecer signos de meningitis, como alteración de la consciencia, déficit neurológico focal o convulsiones no explicados por otra causa, rigidez de nuca, fiebre sin otro foco evidente, fotofobia, aspecto moribundo, signos de disfunción de pares craneales e irritabilidad. Los signos inflamatorios o la exudación purulenta en el trayecto tunelizado o por el orificio de salida del catéter son relativamente frecuentes ${ }^{1,3,6,8}$.

La clínica varía según el microorganismo que está ocasionando la infección: S. aureus, estreptococos y bacilos gramnegativos nosocomiales provocan una clínica más aguda, mientras que los estafilococos coagulasa negativos, Corynebacterium spp. y sobre todo Propionibacterium acnes generan una clínica más larvada, oligosintomática y que dificulta y retrasa el diagnóstico'.

Es importante tener en cuenta que, con frecuencia, en casos de ventriculitis la clínica neurológica queda enmascarada con la clínica de la enfermedad por la cual se ha colocado la derivación o con el uso de medicamentos sedantes ${ }^{4}$. Además, en el posoperatorio, tanto precoz como tardío, de algunas afecciones neuroquirúrgicas las manifestaciones clínicas pueden ser más inespecíficas y los signos meníngeos son infrecuentes, pues el LCR infectado de los ventrículos 
no está en contacto con las meninges, o el deterioro neurológico se manifiesta menos y se presenta como único síntoma fiebre sin foco clínico o deterioro del estado general y del nivel de consciencia².

\section{Diagnóstico}

Tras la sospecha clínica de ventriculitis por la aparición de signos y síntomas como los ya descritos, es necesaria una evaluación del paciente en la unidad de cuidados neurocríticos, con una minuciosa revisión de la historia clínica y una completa exploración física, así como extracción de LCR a través de la derivación y eventualmente mediante punción lumbar para realizar cultivos, tinción de Gram y evaluación de propiedades citoquímicas. También se solicitará resonancia magnética cerebral o idealmente una tomografía computada cerebral previamente a la realización de cualquier maniobra diagnóstica invasiva, con el fin de descartar lesiones ocupantes de espacio con efecto de masa significativo ${ }^{3}$, y que además pueda mostrar datos de ventriculitis, como realce ependimario, o signos de mala función valvular, como hidrocefalia, edema periependimario, aumento ventricular con respecto a estudios previos, etc, y mostrar migración del catéter proximal, restos de otros sistemas no retirados 0 , en casos raros, empiemas subdurales o abscesos cerebrales ${ }^{1}$.

El diagnóstico aún genera controversia y en ocasiones es más difícil, debido a que puede cursar con un LCR de características bioquímicas normales o que exista dificultad para la interpretación de los cambios fisicoquímicos que sufre el LCR en los pacientes que requieren una derivación ventricular externa, como por ejemplo aquellos con hemorragia subaracnoidea o intraventricular, o posquirúrgicos de neurocirugía ${ }^{8,9}$.

Se puede lograr una mayor precisión diagnóstica si se obtiene la muestra de LCR por punción del reservorio o de la válvula del catéter. El cultivo de LCR ventricular es positivo en un $90 \%$ de los casos, pero hasta en un $10 \%$ solo se confirma el diagnóstico cuando se retira el catéter y su cultivo resulta positivo. La causa de un cultivo negativo puede ser por mal procesamiento de las muestras, por no mantener los cultivos de anaerobios el tiempo necesario o por haber tenido tratamiento antimicrobiano previo; en este último caso, la posibilidad de ser positivo puede bajar del 97 al 53\%1,9. La tinción de Gram es positiva en el $31 \%$ de los casos. El LCR debe ser procesado en medios aerobios y anaerobios; estos últimos deben mantenerse en incubación prolongada (al menos 14 días) ${ }^{1}$.

Bacterias poco virulentas, como P. acnes, Bacillus spp., Corybacterium spp. y algunos estafilococos coagulasa-negativos, aisladas en LCR deben considerarse patógenas y hay que informar al microbiólogo de la sospecha para evitar que sean consideradas contaminantes y para que prolongue el tiempo de incubación'1.

En los pacientes que cursan con hidrocefalia obstructiva no se obtendrá el LCR por punción lumbar, ya que en estos casos es diferente del LCR ventricular, pues no se encuentran comunicados estos dos compartimientos, por lo que su valor clínico es escaso, aparte de que hay riesgo de herniación en casos de hidrocefalias no comunicantes, secundarias a hipertensión intracraneana y efecto de masa1.

EI LCR debe ser extraído con medidas de esterilidad, aplicando antisépticos en la llave de tres vías antes y después de la toma, y luego cubrirla con apósitos estériles impregnados en antisépticos'.

Si al realizar la extracción de LCR se obtiene poco volumen, primero debe enviarse LCR para estudios microbiológicos y el sobrante para bioquímica y recuento. Hay que tener en cuenta que los medios líquidos son más sensibles que los cultivos en placa, ya que se ha observado un $25 \%$ más de aislamientos, aunque es más fácil en los medios líquidos aislar bacterias contaminantes'.

Se ha reportado que la toma de dos muestras de LCR en la primera semana de la derivación y después diariamente permite un diagnostico precoz de infección, pero también hay que tener en cuenta el riesgo de esta con la manipulación frecuente del sistema1.

Según los Centers for Disease Control and Prevention de los EE.UU., el diagnóstico requiere al menos uno de los siguientes criterios:

- Un cultivo de LCR positivo o un método de prueba microbiológica no basado en cultivo de LCR positivo.

- Al menos dos de los siguientes: a) fiebre $\left(>38^{\circ} \mathrm{C}\right)$ o cefalea (en $\leq 1$ año de edad, en lugar de cefalea evaluar hipotermia $<36{ }^{\circ} \mathrm{C}$, apnea, bradicardia o irritabilidad; b) signos meníngeos sin otra causa conocida; c) signos de nervios craneales sin otra causa conocida; y al menos uno de los siguientes: 1) pleocitosis, proteinorraquia e hipoglucorraquia; 2) tinción de Gram de LCR positiva; 3) hemocultivos positivos o método de prueba microbiológica no basado en cultivo de sangre positivo; 4) elevación de las inmunoglobulinas $M$ 
Cirugía y Cirujanos. 2019;87

Tabla 1. Espectro de las infecciones de líquido cefalorraquídeo en pacientes con ventriculostomía

Contaminación

Colonización de la ventriculostomía

Sospecha de infección relacionada con la ventriculostomía

Infección relacionada con la ventriculostomía

Ventriculitis
Cultivo o tinción de Gram aislados de LCR positivo, perfil de proteínas, glucosa y conteo de células en LCR normal

Múltiples cultivos y tinción de Gram de LCR positivos, perfil de proteínas, glucosa y conteo de células en LCR normal, más falta de síntomas clínicos excepto de la fiebre

Disminución progresiva de las cifras de glucosa, aumento del perfil de proteínas, pleocitosis* progresiva en el LCR, en ausencia de cultivo y tinción de Gram de LCR positivos

Disminución progresiva de las cifras de glucosa, aumento del perfil de proteínas, pleocitosis* progresiva en el LCR, uno o más cultivos o tinciones de Gram positivos junto con escasos síntomas clínicos diferentes de la fiebre

Valores bajos de glucosa y altos de proteínas, pleocitosis* en LCR, fiebre asociada a signos clínicos de meningitis (ya descritos)

${ }^{*}$ A expensas de polimorfonucleares ${ }^{9}$.

LCR: líquido cefalorraquídeo.

0 aumento de cuatro veces en sueros pareados de las inmunoglobulinas $\mathrm{G}$ para el patógeno; 5) acompañado de la decisión del médico de iniciar tratamiento antibiótico dirigido, si el diagnóstico se hace antes de la muerte ${ }^{4,6,15}$

Por su parte, Lozier, et al. ${ }^{14}$ proponen criterios para describir el espectro de infección del LCR en el contexto de una ventriculostomía, el cual va desde un LCR contaminado (cultivo positivo o tinción de Gram sin alteraciones citoquímicas del LCR) hasta una ventriculitis (alteraciones citoquímicas del LCR junto con signos clínicos de meningitis) (Tabla 1).

Se ha definido hipoglucorraquia como los valores de glucosa en el LCR $<45 \mathrm{mg} / \mathrm{dl}$, pleocitosis como un conteo de células en el LCR $>10 / \mathrm{mm}^{3}$, y proteinorraquia como una cifra de proteínas en LCR $>45 \mathrm{mg} / \mathrm{dl}^{16}$.

La pleocitosis debe hacer sospechar colonización/ infección, y tienen menos valor la proteinorraquia, la hipoglucorraquia y la alteración de parámetros sistémicos en los momentos iniciales'.

El hemograma puede ser normal o presentar leucocitosis a expensas de los neutrófilos en las infecciones más graves; la velocidad de sedimentación globular y la proteína $C$ reactiva (PCR) pueden ser normales o estar ligeramente elevadas ${ }^{1}$. Se ha observado una correlación positiva entre algunos reactantes de fase aguda y el diagnóstico de ventriculitis, como lo es la concentración de lactato ( $\geq 4 \mathrm{mmol} / \mathrm{l})$ o de interleucina 10 en el LCR, no siendo así las concentraciones plasmáticas de PCR, que tienen una mayor utilidad en la monitorización de la respuesta al tratamiento antibiótico $0^{9,17}$.

En el estudio de Gordon ${ }^{4}$ se encontró que el sTREM-1 (triggering receptor expressed on myeloid cells) es útil para el diagnóstico de ventriculitis, ya que se eleva en el LCR durante esta, y por ello, determinar este marcador podría confirmar el diagnóstico de infección en casos dudosos y discriminar entre colonización e infección.

El diagnóstico diferencial entre ventriculitis química 0 aséptica y ventriculitis infecciosa se realiza en forma retrospectiva una vez obtenido el resultado de los cultivos microbiológicos ${ }^{8,18}$. Otros diagnósticos diferenciales pueden ser cualquier causa de mala función valvular, como obstrucción de los catéteres, desconexión, degradación y rotura del catéter, o migración de los extremos proximal o distal, pero la fiebre, las crisis convulsivas, la elevación de la PCR y las alteraciones citoquímicas son más frecuentes en las infecciones. También hay que descartar infecciones virales o bacterianas en otra localización, como respiratorias, gastrointestinales o genitourinarias, entre otras, y así evitar la realización de extracciones o de punciones innecesarias $^{1}$ (Fig. 1).

\section{Tratamiento}

Una vez se tenga el diagnóstico de ventriculitis debe iniciarse tratamiento antibiótico de inmediato, pues el reconocimiento y el inicio precoz del tratamiento está relacionado con el pronóstico del paciente. Si no es conocido el agente causal se iniciará tratamiento antibiótico empírico, mientras se tienen resultados microbiológicos, teniendo en cuenta las condiciones que indicaron la colocación de la ventriculostomia y la flora bacteriana local; en casos de trauma cerebral cerrado deben sospecharse Streptococcus pneumoniae, Haemophilus influenzae y estreptococos beta hemolíticos del grupo $\mathrm{A}$, y si fue un trauma penetrante de cráneo o es una infección posquirúrgica podrían estar implicados $S$. aureus, estafilococos coagulasa negativos, en especial 




Figura 1. Algoritmo diagnóstico de la ventriculitis. LCR: líquido cefalorraquídeo; PCR: proteína C reactiva; VSG: velocidad de sedimentación globular.

S. epidermidis, o bacilos gramnegativos aerobios, en especial $P$. aeruginosa ${ }^{2,17,18}$.

Por lo anterior, se recomienda iniciar cobertura con vancomicina o linezolid o teicoplanina más una cefalosporina de tercera o cuarta generación, o meropenem más rifampicina; también se pueden usar colistina y cotrimoxazol. En todos estos casos, si el paciente es alérgico a los betalactámicos, se sustituirá el meropenem por levofloxacino, aztreonam o cloranfenicol ${ }^{9,12,15,17,18}$ (Tabla 2).

Si no se tienen resultados de cultivo de LCR, la tinción de Gram puede orientar el tratamiento empírico de la siguiente forma: si es negativa, debido a que las bacterias más frecuentes son estafilococos, bacilos gramnegativos y $P$. acnes, el tratamiento debe ser con vancomicina más ceftazidima o cefepima o meropenem; si se observan cocos grampositivos, solo se da vancomicina; y si son bacilos gramnegativos, el tratamiento será con ceftazidima, cefepima o meropenem¹.
Obtenido el resultado del cultivo, el tratamiento se adecua al microorganismo específico de acuerdo con su sensibilidad9,18 (Tabla 3).

La extracción de LCR para evaluar la respuesta al tratamiento no es de gran utilidad, ya que los rangos de los valores de proteínas y glucosa en el LCR son variables, y además puede persistir la pleocitosis aun sin la presencia de bacterias; así, el mejor indicador de respuesta al tratamiento es la mejoría de los signos clínicos. Sin embargo, se recomienda, aunque no sistemáticamente, realizar extracciones de control del LCR cuando no hay mejoría a las 48-72 horas de iniciado el tratamiento y después de 2 o 3 días de iniciado el tratamiento antibiótico para gérmenes multirresistentes; en estos casos, se recomienda monitorizar la evolución cada 3 días mediante análisis fisicoquímico y cultivo del LCR $^{17}$.

Hay que tener en cuenta que, a pesar de una terapia apropiada y una buena respuesta clínica, los 
Tabla 2. Posología de los medicamentos en la ventriculitis $9,12,15,17,18$

\begin{tabular}{|c|c|c|c|}
\hline Antibiótico & Dosis intravenosa en niños & Dosis intravenosa en adultos & Dosis intraventricular \\
\hline Amikacina & $7.5 \mathrm{mg} / \mathrm{kg} / 8 \mathrm{~h}$ & $5 \mathrm{mg} / \mathrm{kg} / 8 \mathrm{~h}$ & 5-50 mg/día \\
\hline Ampicilina & $100 \mathrm{mg} / \mathrm{kg} / 6 \mathrm{~h}$ & $2 \mathrm{mg} / 4 \mathrm{~h}$ & \\
\hline Amfotericina B & $3-5 \mathrm{mg} / \mathrm{kg} / 24 \mathrm{~h}$ & & 0.1-1 mg/día \\
\hline Aztreonam & $40 \mathrm{mg} / \mathrm{kg} / 8 \mathrm{~h}$ & $2 \mathrm{~g} / 6-8 \mathrm{~h}$ & \\
\hline Cefepima & $50 \mathrm{mg} / \mathrm{kg} / 8 \mathrm{~h}$ & $2 \mathrm{~g} / 8 \mathrm{~h}$ & \\
\hline Cefotaxima & & $2 g / 4-6 h$ & \\
\hline Ceftazidima & $50 \mathrm{mg} / \mathrm{kg} / 8 \mathrm{~h}$ & $2 \mathrm{~g} / 6-8 \mathrm{~h}$ & \\
\hline Ceftriaxona & $50 \mathrm{mg} / \mathrm{kg} / 12 \mathrm{~h}$ & $2 \mathrm{~g} / 12-24 \mathrm{~h}$ & \\
\hline Ciprofloxacino & $10 \mathrm{mg} / \mathrm{kg} / 8 \mathrm{~h}$ & $400 \mathrm{mg} / 8-12 \mathrm{~h}$ & \\
\hline Cloranfenicol & & $1-2 \mathrm{~g} / 6 \mathrm{~h}$ & \\
\hline Cloxacilina & & $2 \mathrm{~g} / 4 \mathrm{~h}$ & \\
\hline Colistina & $2.5 \mathrm{mg} / \mathrm{kg} / 12 \mathrm{~h}$ & & 10-20 mg/día \\
\hline Cotrimoxazol & $5 \mathrm{mg} / \mathrm{kg} / 6-12 \mathrm{~h}$ & $5 \mathrm{mg} / \mathrm{kg} / 6-12 \mathrm{~h}^{*}$ & \\
\hline Gentamicina & $2.5 \mathrm{mg} / \mathrm{kg} / 8 \mathrm{~h}$ & $5 \mathrm{mg} / \mathrm{kg} / 8-24 \mathrm{~h}$ & 1-10 mg/día \\
\hline Daptomicina & $6-10 \mathrm{mg} / \mathrm{kg} / 12 \mathrm{~h}$ & $6-10 \mathrm{mg} / \mathrm{kg} / 24 \mathrm{~h}$ & 2-5 mg/día o 10 mg/72 h \\
\hline Flucitosina & & $25 \mathrm{mg} / \mathrm{kg} / 6 \mathrm{~h}$ & \\
\hline Fluconazol & $12 \mathrm{mg} / \mathrm{kg} / 24 \mathrm{~h}$ & $400-800 \mathrm{mg} / 12-24 \mathrm{~h}$ & \\
\hline Levofloxacino & & $500 \mathrm{mg} / 12 \mathrm{~h}$ & \\
\hline Linezolid & & $600 \mathrm{mg} / 12 \mathrm{~h}$ & \\
\hline Meropenem & $40 \mathrm{mg} / \mathrm{kg} / 8 \mathrm{~h}$ & $1-2 g / 6-8 h$ & \\
\hline Moxifloxacino & & $400 \mathrm{mg} / 24 \mathrm{~h}$ & \\
\hline Penicilina G & $75.000 \mathrm{UI} / \mathrm{kg} / 6 \mathrm{~h}$ & 4 millones UI/6 $\mathrm{h}$ & \\
\hline Polimixina B & & & $5 \mathrm{mg} / \mathrm{día}$ \\
\hline Rifampicina & $20 \mathrm{mg} / \mathrm{kg} / 24 \mathrm{~h}$ & $600 \mathrm{mg} / 24 \mathrm{~h}$ & \\
\hline Teicoplanina & & $200 \mathrm{mg} / 12 \mathrm{~h}^{\dagger}$ & 5-40 mg/día \\
\hline Tobramicina & $2.5 \mathrm{mg} / \mathrm{kg} / 8 \mathrm{~h}$ & $5 \mathrm{mg} / \mathrm{kg} / 8-24 \mathrm{~h}$ & 5-20 mg/día \\
\hline Vancomicina & $15 \mathrm{mg} / \mathrm{kg} / 6 \mathrm{~h}$ & $10-25 \mathrm{mg} / \mathrm{kg} / 8-12 \mathrm{~h}^{\ddagger}$ & 5-40 mg/día \\
\hline Voriconazol & & $6 \mathrm{mg} / \mathrm{kg} / 12 \mathrm{~h}$ & \\
\hline
\end{tabular}

*Dosis aplicable a la cantidad de trimetoprima.

${ }^{t}$ Dosis inicial de $400 \mathrm{mg} / 12 \mathrm{~h}$ (las tres primeras dosis); se puede administrar la dosis cada 48 horas.

‡Puede aplicarse en infusión continua y monitorizar sus concentraciones plasmáticas.

cultivos de LCR pueden continuar positivos incluso 2 semanas después de haber iniciado el tratamiento ${ }^{18}$.

La administración de antibióticos por vía intraventricular se ha usado de forma empírica, pues no hay suficientes datos sobre la distribución, la eliminación y la toxicidad de la mayoría de los antibióticos por esta vía. Además, podría haber dificultad por la presencia de sinequias, débitos elevados de LCR, imposibilidad de cerrar el drenaje ventricular (para facilitar la distribución del fármaco) o intolerancia. No obstante, esta vía es útil en los casos en que fracasa el tratamiento sistémico, hay infecciones por gérmenes multirresistentes, hay gérmenes sensibles a fármacos con una pobre penetración en el LCR, existe dificultad o imposibilidad de retirar material extraño del SNC (abscesos, catéteres, válvulas) o hay alguna contraindicación relativa para el tratamiento antibiótico sistémico, como enfermedad renal. La administración intraventricular debe ser realizada por 
Tabla 3. Tratamiento específico de las ventriculitis

\begin{tabular}{|c|c|c|}
\hline Microorganismo & Tratamiento de elección & Tratamiento alternativo \\
\hline \multicolumn{3}{|l|}{$\begin{array}{l}\text { S. aureus y } \\
\text { Estafilococos coagulasa } \\
\text { negativos (S. epidermidis) }\end{array}$} \\
\hline Sensible a meticilina & Cloxacilina \pm rifampicina & Vancomicina o \\
\hline Resistente a meticilina & Vancomicina \pm rifampicina & $\begin{array}{l}\text { Linezolid } \pm \text { rifampicina } \\
\text { Linezolid } \pm \text { rifampicina }\end{array}$ \\
\hline \multicolumn{3}{|l|}{ S. pneumoniae } \\
\hline CMI penicilina<0,1 mg/l & Penicilina G/ampicilina & Cloranfenicol o \\
\hline CIM 0,1-1mg/l & Ceftriaxona/cefotaxima & vancomicina + rifampicina \\
\hline CMI penicilina $\geq 2$ mg/l o CMl & Vancomicina + ceftriaxona/ & o linezolid o \\
\hline centraxona/cerotaximaz I mg/l & & fluoroquinolona \\
\hline \multicolumn{3}{|l|}{ H. influenzae } \\
\hline Productor de betalactamasas & Ampicilina & Cloranfenicol o aztreonam \\
\hline $\begin{array}{l}\text { No productor de } \\
\text { betalactamasas }\end{array}$ & Ceftriaxona/cefotaxima & \\
\hline \multicolumn{2}{|l|}{ Enterococcus spp. } & Meropenem+aminoglucósido \\
\hline Sensible a ampicilina & Ampicilina+aminoglucosidos & 0 \\
\hline Resistentes a ampicilina & Vancomicina o linezolid + aminoglucósido & vancomicina o \\
\hline $\begin{array}{l}\text { Resistentes a ampicilina y } \\
\text { vancomicina }\end{array}$ & Linezolid + imipenem o ceftriaxona & linezolid + aminoglucósido \\
\hline$P$. aeruginosa & $\begin{array}{l}\text { Ceftazidima o } \\
\text { cefepima }+ \text { aminoglucósido } \pm \text { tobramicina } \\
\text { intraventricular, o } \\
\text { meropenem } \pm \text { aminoglucósido }\end{array}$ & $\begin{array}{l}\text { Aztreonam + tobramicina } \\
\text { intravenosa } \pm \text { intraventricular o } \\
\text { ciprofloxacino }\end{array}$ \\
\hline \multicolumn{3}{|l|}{ Acinetobacter baumannii } \\
\hline $\begin{array}{l}\text { Sensible a los carbapenémicos } \\
\text { Resistente a los } \\
\text { carbapenémicos }\end{array}$ & $\begin{array}{l}\text { Meropenem } \pm \text { colistina intraventricular } \\
\text { Colistina intravenosa } \pm \text { colistina } \\
\text { intraventricular }\end{array}$ & Tigeciclina \\
\hline Enterobacterias & $\begin{array}{l}\text { Ceftriaxona o cefotaxima o } \\
\text { meropenem }\end{array}$ & $\begin{array}{l}\text { Ciprofloxacino o } \\
\text { aztreonam }\end{array}$ \\
\hline Candida spp. & Amfotericina $\mathrm{B} \pm$ flucitosina & Fluconazol o voriconazol \\
\hline
\end{tabular}

CMl: concentración mínima inhibitoria.

personal médico. Los fármacos se administran diluidos en 2 a 5 cc de solución salina, tras extraer previamente la misma cantidad de LCR para evitar hipertensión intracraneal, e interrumpir la eliminación de LCR por 1 a 3 horas. Esta vía de administración no ha sido aprobada por la Food and Drug Administration en los EE.UU. 8, 8, 12,17-19 (Tabla 2).

El tratamiento intraventricular debe ser monitorizado periódicamente con toma de muestra de LCR en el valle, y se ajustará la dosis para lograr un cociente inhibitorio (concentración valle en LCR/concentración mínima inhibitoria en LCR) del antibiótico en LCR mayor de 10. Como ya se ha advertido, la manipulación frecuente de la derivación hace que las complicaciones infecciosas y los accidentes sean más frecuentes ${ }^{17}$.

Cuando no haya contraindicación absoluta para retirar el catéter (riesgo quirúrgico alto 0 mal pronóstico a corto plazo), según si es o no necesaria la permanencia de la ventriculostomía, el tipo de hidrocefalia y la preferencia del neurocirujano, se debe retirar la derivación lo más pronto posible. De esta forma se tienen varias opciones para proceder $^{1,17}$ :

- Si el paciente necesita la derivación permanente y presenta hidrocefalia obstructiva, se prosigue con las siguientes opciones:

a) Si la derivación es permeable, hay mejoría clínica y del LCR, permanecer con el catéter ventricular externo que permite aliviar la hipertensión endocrina y drenar el LCR infectado. Tras 3-5 días de tratamiento antibiótico con esterilización de los ventrículos, se retirará el catéter y se colocará un drenaje ventricular externo en el ventrículo contralateral, continuando el tratamiento antibiótico. 


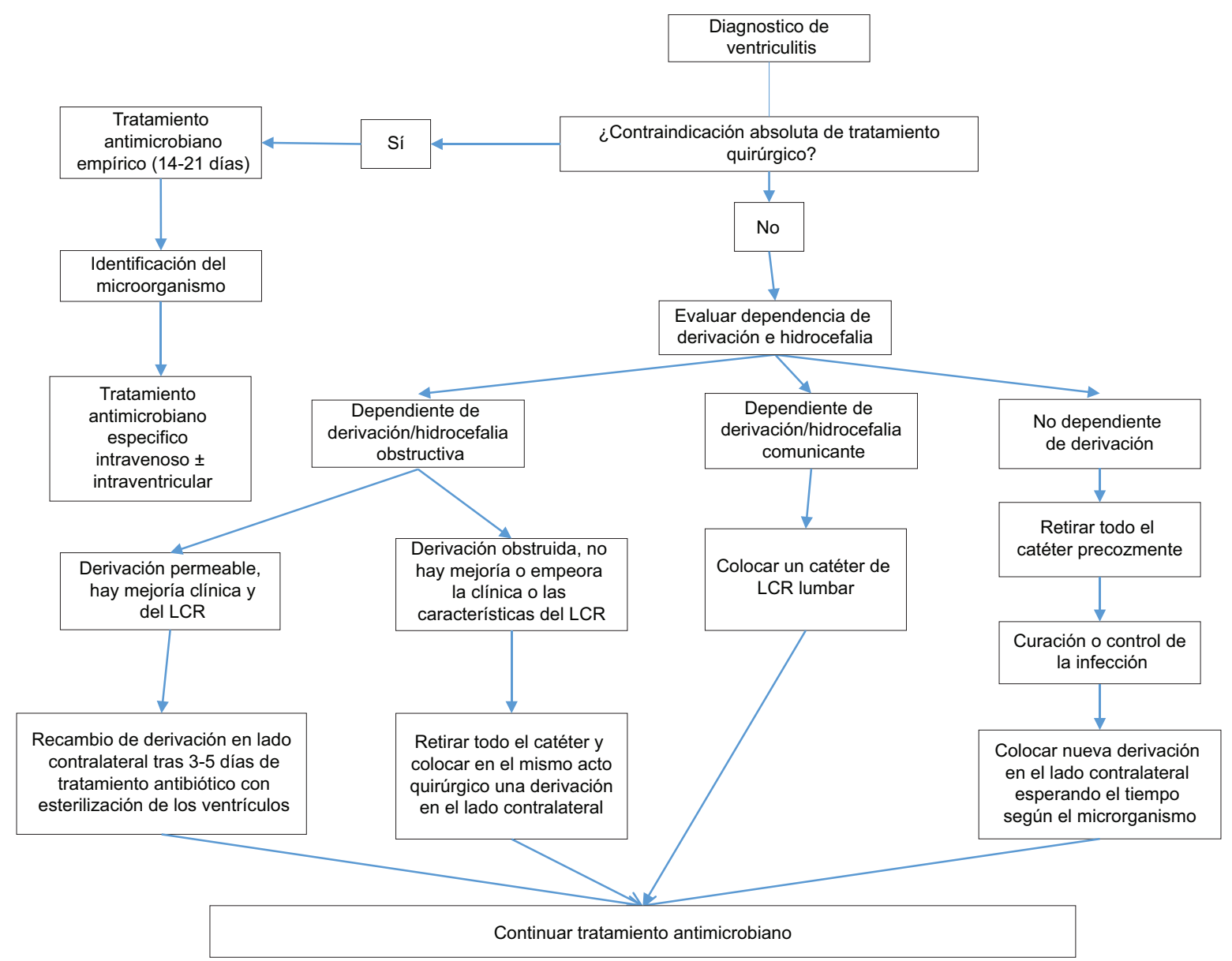

Figura 2. Algoritmo de tratamiento de la ventriculitis. LCR: líquido cefalorraquídeo.

b) Si la derivación está obstruida, no hay mejoría o empeoran la clínica o las características del LCR, retirar todo el catéter infectado y colocar en el mismo acto quirúrgico un catéter ventricular externo en el lado contralateral. Si el paciente necesita de forma permanente la derivación y presenta una hidrocefalia comunicante, se recomienda colocar un catéter lumbar para el drenaje externo del LCR.

- Si el paciente puede estar sin drenaje del LCR temporalmente, se debe retirar precozmente el catéter infectado junto al tratamiento antibiótico. Una vez curada o controlada la infección con el tratamiento antibiótico, se colocará el nuevo sistema en el lado contralateral.

El manejo de las ventriculitis causadas por microorganismos resistentes incluye la extracción de la derivación y aparte del antibiótico adecuado por vía intravenosa ${ }^{19}$.

El momento apropiado para volver a colocar la derivación depende del agente causal de la infección, de la respuesta inicial al tratamiento antibiótico y de la retirada del sistema infectado. En los pacientes con infección por gérmenes menos agresivos, como estafilococos coagulasa negativos, $P$. acnes o Corynebacterium spp., y sin signos graves de ventriculitis, la recolocación puede realizarse tras 7 días de negativización del cultivo de LCR. En los casos más graves, o cuando el agente causal es $S$. aureus, debe prolongarse la recolocación a no menos de 10 días. En los casos producidos por bacilos gramnegativos o flora mixta se debe recolocar no antes de 14 días ${ }^{1,17}$.

Birbilis, et al. ${ }^{10}$ proponen que los catéteres de ventriculostomía externa de metal podrían ser una opción en el manejo de ventriculitis prolongadas que son resistentes al tratamiento con dispositivos habituales, y en infecciones complicadas.

La duración del tratamiento antibiótico no será inferior a 21 días, tanto por vía intravenosa como intraventricular, en especial cuando se trate de infecciones por bacilos gramnegativos (enterobacterias, P. aeruginosa, Acinetobacter spp.), Streptococcus agalactiae o enterococos, por lo que hay riesgo de recurrencia de la infección con tratamientos más cortos. En casos 
Tabla 4. Recomendaciones para la prevención de la ventriculitis

\begin{tabular}{|c|c|}
\hline - Seguir protocolos estériles y listas de chequeo & - Realización del procedimiento por parte de un neurocirujano experto \\
\hline - Realizar la ventriculostomía en sala de cirugía & - Realizar el procedimiento a primera hora en la mañana \\
\hline - Realizar el procedimiento en el menor tiempo posible & - Reducir el tráfico y el número de personas en la sala de cirugía \\
\hline $\begin{array}{l}\text { - Colocar la cabeza del paciente lejos de la puerta de entrada de } \\
\text { la sala }\end{array}$ & $\begin{array}{l}\text { - Corte del cabello en el sitio de la incisión o punción con tijeras antes } \\
\text { del procedimiento }\end{array}$ \\
\hline $\begin{array}{l}\text { - Adecuada asepsia y antisepsia del campo con clorhexidina o } \\
\text { yodo con compresas estériles }\end{array}$ & - Frotarse las manos con yodo o clorhexidina \\
\hline $\begin{array}{l}\text { - Reducir el tamaño de exposición de superficies cutáneas } \\
\text { durante la intervención }\end{array}$ & - Reducir la manipulación del catéter en la intervención \\
\hline - Realizar tunelización del catéter subcutánea de más de $5 \mathrm{~cm}$ & - Anclar el catéter a la piel en el sitio de salida del túnel subcutáneo \\
\hline $\begin{array}{l}\text { - Usar técnica de tunelización mejorada, usando una aguja de } \\
\text { trocar }\end{array}$ & $\begin{array}{l}\text { - Punción con aguja percutánea, uso de aguja fina de Duisburger o } \\
\text { tercera ventriculostomía endoscópica sola o con cauterización del } \\
\text { plexo coroideo }\end{array}$ \\
\hline - Usar un sistema de derivación cerrado & - Inyección de antibiótico en el depósito de la derivación \\
\hline $\begin{array}{l}\text { - Administración profiláctica de antibióticos sistémicos } \\
\text { prolongados* (antes y hasta } 24 \text { horas después de la inserción) }\end{array}$ & $\begin{array}{l}\text { - Uso de catéteres impregnados con antibiótico, o de plata o metal } \\
\text { flexible }^{\dagger}\end{array}$ \\
\hline - Evitar fugas de líquido cefalorraquídeo & - Vestimenta estéril por parte del personal \\
\hline $\begin{array}{l}\text { - Ensamblar el sistema de drenaje externo estéril en la operación } \\
\text { dentro del campo estéril }\end{array}$ & $\begin{array}{l}\text { - Ensamblar el dispositivo de monitoreo de la presión intracraneal } \\
\text { estéril en el sistema de drenaje externo sin contacto directo con el } \\
\text { sitio de la operación }\end{array}$ \\
\hline $\begin{array}{l}\text { - Sistema de drenaje externo envuelto con gel antibacteriano en } \\
\text { gasa estéril y cerrado con material a prueba de agua en todos } \\
\text { los puntos de conexión }\end{array}$ & $\begin{array}{l}\text { - Aplicar antiséptico después de cerrar puntos de inserción en la piel } \\
\text { y uso de un vendaje tras la inserción estéril con antiséptico }\end{array}$ \\
\hline $\begin{array}{l}\text { - Vaciar la bolsa de drenaje solo cuando esté llena y cambiarla } \\
\text { una vez a la semana }\end{array}$ & - Disminuir la manipulación del borde de la piel y del implante \\
\hline $\begin{array}{l}\text { - Aplicar medidas cada vez que se manipule el catéter ventricular, } \\
\text { como cambios de guantes, doble guante, tapabocas, etc. }\end{array}$ & $\begin{array}{l}\text { - Reducir al mínimo necesario la toma de muestras de líquido } \\
\text { cefalorraquídeo y la manipulación del sistema de drenaje }\end{array}$ \\
\hline - No enjuague ni irrigación del catéter & $\begin{array}{l}\text { - Curar el punto de inserción cada } 24 \text { horas y siempre que el apósito } \\
\text { esté manchado o despegado }\end{array}$ \\
\hline $\begin{array}{l}\text { - Evitar la punción del reservorio y la aparición de infección de las } \\
\text { heridas quirúrgicas o decúbitos }\end{array}$ & $\begin{array}{l}\text { - Retirar la derivación y volver a colocar otro catéter en un sitio } \\
\text { diferente después de } 5 \text { días de su colocación }\end{array}$ \\
\hline $\begin{array}{l}\text { - Retirar lo más pronto posible la derivación cuando ya no sea } \\
\text { necesaria, bajo estricta técnica aséptica }\end{array}$ & $\begin{array}{l}\text { - Si ya ha habido infección se debe retirar todo el catéter y los restos } \\
\text { de otros (si los hubiera) }\end{array}$ \\
\hline
\end{tabular}

*Cefalosporina antiestafilocócica.

†Impregnados en minociclina+rifampicina o clindamicina+rifampicina, y en algunos centros se impregnan empíricamente en vancomicina o teicoplanina.

de estafilococos coagulasa negativos con escasa reacción inflamatoria, y en aquellos pacientes que evolucionan bien tras la retirada del drenaje ventricular, se recomienda tratamiento antibiótico por un lapso de 10-14 días ${ }^{17}$. No se debe suspender el tratamiento hasta antes de obtener dos o tres cultivos negativos luego del inicio del tratamiento, y se debe continuar hasta 3 días más ${ }^{8}$.

Hay que tener claro que el tratamiento antimicrobiano provoca una mejora inicial, o curación aparente, pues se eliminan las bacterias superficiales de la biocapa, pero no elimina las bacterias más profundas estacionarias, y debido a esto puede haber recurrencia si no se retira la derivación. Por tal motivo, el tratamiento siempre es médico-quirúrgico (Fig. 2).

\section{Recomendaciones}

En la tabla 4 se presentan las recomendaciones para la prevención de la ventriculitis tras la colocación de un drenaje ventricular externo $0^{1,3-5,7,9,10,13-15,18,20}$.

\section{Conclusiones}

La ventriculitis posterior a una ventriculostomía es una complicación neuroquirúrgica con elevada 
morbimortalidad. Su diagnóstico precoz es difícil debido a que los signos clínicos y paraclínicos se solapan con los de la afección que motivó la colocación de la derivación, y por falta de unificación de los criterios diagnósticos. Su diagnóstico y tratamiento precoces mejoran la sobrevida, pero la aparición de resistencia antibiótica complica el tratamiento antimicrobiano. La reducción de las infecciones por catéter ventricular disminuirá el tiempo de hospitalización y los costos para el paciente y el sistema de salud, lo cual debe convertirse en el objetivo fundamental. Se hace necesaria la realización de investigaciones en torno a los criterios diagnósticos y a la efectividad y la seguridad del tratamiento intraventricular.

\section{Bibliografía}

1. Jiménez M, García E. Infecciones relacionadas con los sistemas de drenaje de líquido cefalorraquídeo. Enferm Infecc Microbiol Clin. 2008;26:240-51.

2. Martínez L, Aveiro A. Ventriculitis asociada a drenaje ventricular externo. Rev Virtual Soc Parag Med Int. 2017;4:46-56.

3. Grille P, Costa, G, Biestro A, Wajskopf S. Manejo del drenaje ventricular externo en la unidad de cuidados intensivos. Guía práctica. Rev Med Urug. 2007;23:50-5.

4. Gordon M. Fiosiopatogenia y diagnóstico de la ventriculitis asociada a drenaje ventricular externo. Barcelona: Universidad de Barcelona; 2015.

5. Lewis A, Czeisler B, Lord A. Variations in strategies to prevent ventriculostomy-related infections: a practice survey. Neurohospitalist. 2017;7:15-23.
6. Lewis A, Wahlster S, Karinja A, Czeisler B, Kimberly W, Lord A. Ventriculostomy-related infections (VRI): the performance of different definitions for diagnosing infection. Br J Neurosurg. 2016;30:49-56.

7. Stenehjem E, Armstrong W. Central nervous system device infections. Infect Dis Clin North Am. 2012;26:89-110.

8. Villegas $R$, Camputaro L. Infección relacionada con el drenaje ventricular externo: tratamiento intravenoso versus intratecal. Revision de la literatura. Rev Argent Neurocir. 2006;20:133-6.

9. García-Vázquez E, Gómez J. Tratamiento de las infecciones relacionadas con procedimientos neuroquirúrgicos. Rev Esp Quimioterap. 2007;20:36-43.

10. Birbilis T, Matis G, Chrysou O, Karakosta E, Themelidis D, Panopoulou M. Metal external ventricular drainage catheters in the treatment of persistent ventriculitis - an old story made new: technical note and preliminary results. Turk Neurosurg. 2013;23:420-5.

11. Hoefnagel D, Dammers R, Ter Laak-Poort M, Avezaat C. Risk factors for infections related to external ventricular drainage. Acta Neurochir (Wien). 2008;150:209-14.

12. Feo O, Rueda D. Providencia stuartii asociada a ventriculostomía. Reporte de un caso. Univ Med. 2012;53:452-8.

13. Worley E, Astle S, Watson J. Prospective evaluation of ventriculostomy infections. Cureus. 2015;7:e312.

14. Lozier A, Sciacca R, Romagnoli M, Connolly E. Ventriculostomy-related infections: a critical review of the literature. Neurosurgery. 2002;51:170 82.

15. Hasbun R. Central nervous system device infections. Curr Infect Dis Rep. 2016;18:34.

16. Bari M, Haider G, Malik K, Waqas M, Mahmood S, Siddiqui M. Outcomes of post-neurosurgical ventriculostomy-associated infections. Surg Neurol Int. 2017;8:124.

17. Hospital Povincial de Neuquén. Dr. Castro Rendón. Guía de práctica clínica, diagnóstico y tratamiento de la meningitis posquirúrgica y la ventriculitis en pacientes adultos internados. 2010. Disponible en: http:// www.saludneuquen.gob.ar/wp-content/uploads/2016/10/13-GPC-Meningitis-post-quirurgica-HPN-2010.pdf

18. Servicio Aragonés de Salud. Manejo de los drenajes ventriculares. Aragon; 2012. Disponible en: http://www.ics-aragon.com/cursos/enfermo-critico/4/Drenajes.pdf

19. Spanu T, Rigante D, Tamburrini G, Fiori B, D'Inzeo T, Posteraro B, et al. Ventriculitis due to Staphylococcus lugdunensis: two case reports. J Med Case Rep. 2008;2:267.

20. Tse T, Cheng K, Wong K, Pang K, Wong C. Ventriculostomy and infection: a 4-year-review in a local hospital. Surg Neurol Int. 2010;1:47. 